\title{
Surface Chemistry for Improvement in Load-Carrying Capacity of Poly(Ether-Ether-Ketone)-Based Materials by Poly(Tetrafluoroethylene)
}

\author{
Ichiro Minami $^{1{ }^{*}}$, Tomoo Kubo ${ }^{1)}$, Hidetaka Nanao ${ }^{1)}$, Shigeyuki Mori ${ }^{1)}$, Hideki Iwata $^{2)}$ and Masahito Fujita ${ }^{2)}$ \\ ${ }^{1)}$ Department of Chemical Engineering, Faculty of Engineering, Iwate University \\ 4-3-5 Ueda, Morioka, Iwate 020-8551, Japan \\ ${ }^{2)}$ Central R\&D Material Research Dept., Daido Metal Co. Ltd. \\ Tendoh Shinden, Maehara, Inuyama, Aichi 484-0061, Japan \\ *Corresponding author: ichiro@iwate-u.ac.jp
}

( Manuscript received 12 March 2008; accepted 27 May 2008; published 15 June 2008 )

\begin{abstract}
The tribological properties of poly(ether-ether-ketone) (PEEK) against steel was evaluated by a ring-on-flat type tribo-test under rotating motion. Addition of poly(tetrafluoroethlene) (PTFE) as solid lubricants improved the load-carrying capacity of the material. The role of PTFE was studied by means of time of flight secondary ion mass spectroscopy (TOF-SIMS). The transfer of PTFE from the PEEK surface onto steel surface was found to be beneficial for preventing seizure.
\end{abstract}

Keywords: lightweight tribo-material, white metal, Babbit alloy, solid lubricant, PEEK, PTFE, TOF-SIMS, tribo-chemistry

\section{Introduction}

Babbitt alloys, so-called white metals, are widely employed in bearings as wear resistance tribo-material. Since the operating conditions in bearings are getting harder, materials for those applications have to be improved. Unfortunately, tribological properties of Babbitt alloys are usually insufficient under heavy load conditions. Therefore new materials that possess better tribological properties are desired; we focused on possibility of polymer-based materials. A benefit of the polymer-based materials is possibility of lightweight materials that leads energy saving. Synthetic polymers (density ranging from 1 to $2 \mathrm{~g} / \mathrm{cm}^{-3}$ ) are better candidates than lightweight metal alloys (density ranging from 4 to $5 \mathrm{~g} / \mathrm{cm}^{-3}$ ). In fact, polymer-based materials have come to apply in mechanical elements such as gears and bearings.

One of candidates for Babbitt alloy alternatives is poly-ether-ether-ketone [PEEK, or formally poly (phenoxyphenylphenylketone)]. They are well known to exhibit good thermal properties. Improvement in mechanical strength of them is achieved by filling carbon fibers ${ }^{1,2)}$. Blending of poly(tetrafluoroethlene) (PTFE) in PEEK have been reported to reduce wear rate and friction ${ }^{3-8)}$ under dry conditions. In this work, the load-carrying capacities of PEEK-PTFE composite were evaluated and the mechanism was investigated with an emphasis on the role of PTFE on the tribological properties from a viewpoint of surface chemistry.

\section{Experimental}

A thrust type tribo-tester (Figure 1) was employed to evaluate the load-carrying capacity under the conditions listed in Table 1. The composite materials were slid against steel. The contact stress was programmed to increase by $1 \mathrm{MPa}$ every 10 minutes. The seizure load was judged when the torque raised more than $50 \mathrm{~N}$ or the oil temperature raised more than $150{ }^{\circ} \mathrm{C}$. The contents of PTFE in PEEK composite were in the range of 0-6 mass $\%$. A Babbitt alloy (3 mass $\%$ of $\mathrm{Cu}, 7$ mass $\%$ of $\mathrm{Sb}$, and balance of $\mathrm{Sn}$ ) was selected as the reference. The conditions for TOF-SIMS analysis are given in Table 2.

\section{Results and discussion}

Island-like particles of PTFE were found on a virgin PEEK-PTFE surface by an optical microscope and an EPMA analysis. However, chemical mapping by TOF-SIMS indicates that PTFE spreads as thin film over PEEK surface (Figure 2). The results can be explained by surface sensitivity of the analysis. The EPMA shows average contents on the surfaces of $1 \mu \mathrm{m}$ depth, while TOF-SIMS detects the uppermost surfaces of 1-2 $\mathrm{nm}^{9}$. Results of the tribo-test are summarized in Figure 3. The conventional material, Babbitt alloy, showed the seizure pressure of 8-9 $\mathrm{MPa}$. 

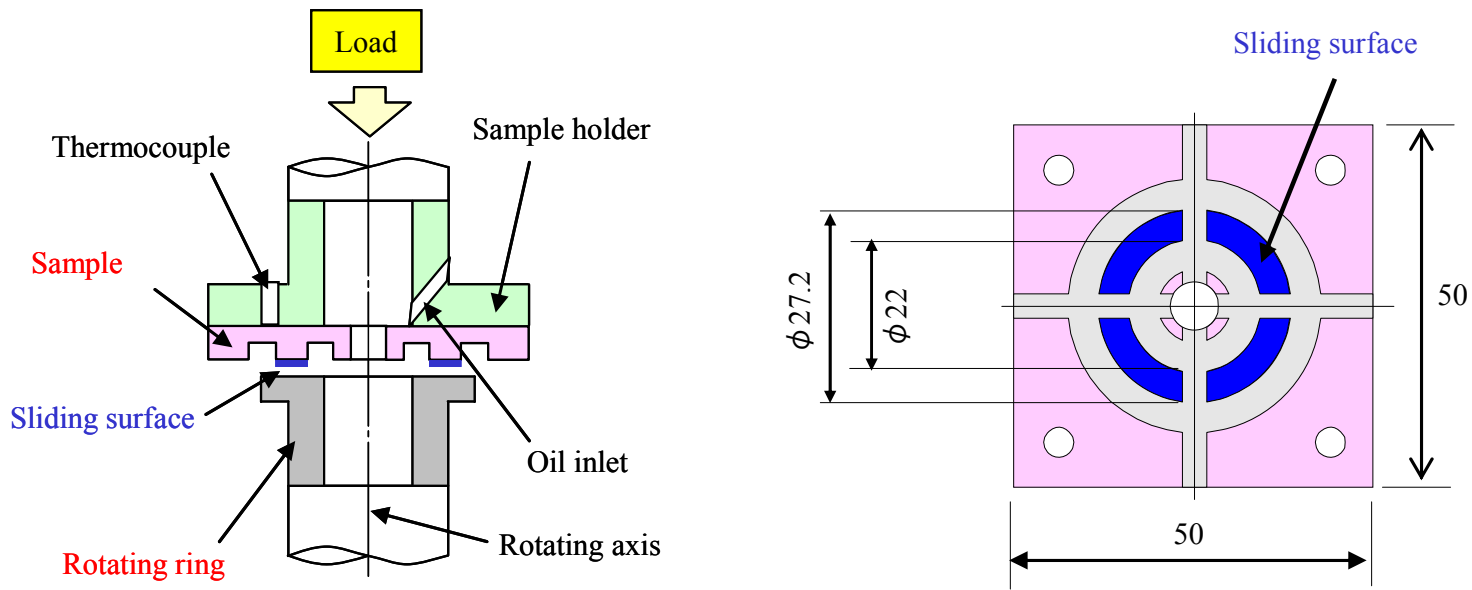

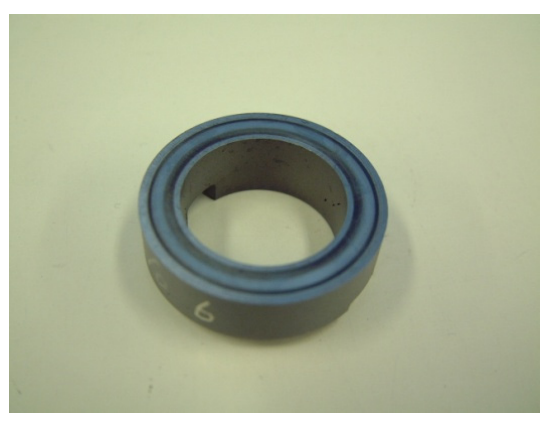

(a) Rotating ring ( $\mathrm{S} 35 \mathrm{C}$ steel)

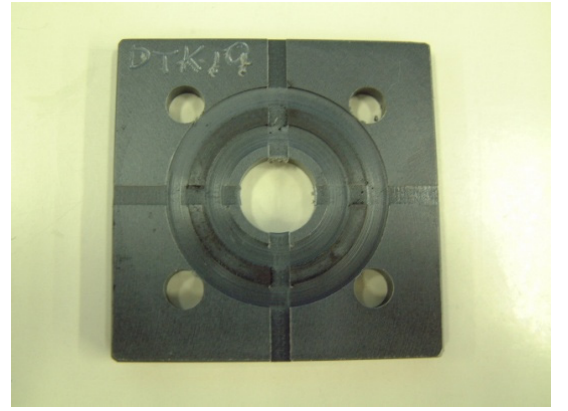

(b) Sample (PEEK)

Figure 1 Outline of tribo-tester and test sample

PEEK provided higher seizure pressure, ranging 9-11 $\mathrm{MPa}$. The blending of PTFE, even at the concentration of 0.5 mass $\%$, considerably improved the load-carrying capacity of PEEK. Seizure was not observed at $12 \mathrm{MPa}$ of the contact pressure that is the maximum load of the tribo-tester. It has been reported that 7.5-20 mass $\%$ of PTFE is required for improvement in the tribological properties of PEEK under dry conditions ${ }^{3-8)}$. Much lower concentrations of PTFE are enough to prevent seizure under the lubricated conditions.

We were much interested in the role of PTFE on the

Table 1 Conditions for the tribo-test

\begin{tabular}{c|c}
\hline Initial contact pressure, $\mathrm{MPa}$ & 1 \\
\hline Increment of contact pressure, $\mathrm{MPa}$ & 1 \\
\hline Final contact pressure, $\mathrm{MPa}$ & 12 \\
\hline Test duration for each step, minute & 10 \\
\hline Sliding velocity, $\mathrm{m} \cdot \mathrm{s}^{-1}$ & 2 \\
\hline Oil grade & ISO VG32 \\
\hline Initial oil temperature, ${ }^{\circ} \mathrm{C}$ & 40 \\
\hline Flow rate of oil inlet, $\mathrm{m}^{3} \cdot \mathrm{min}^{-1}$ & $2.0 \times 10^{-5}$ \\
\hline
\end{tabular}

load-carrying capacity of PEEK from view points of surface chemistry. Chemical mapping of the rubbed PEEK surfaces indicates that contents and distribution of PTFE were changed during the tribo-test (Figure 4). The island-like area of PTFE was disappeared after the

Table 2 Conditions for the TOF-SIMS analysis

\begin{tabular}{c|c}
\hline Instrument & $\begin{array}{c}\text { Physical } \\
\text { Electronics TFS- } \\
2100 \text { (TRIFT-II) }\end{array}$ \\
\hline Resolution at m/z 26.98 (Al) & $\mathrm{M} / \triangle \mathrm{M}>5000$ \\
\hline Primary ion & bunched Ga $^{+}$ \\
\hline Impact energy, keV & 15 \\
\hline Ion current for one pulse, $\mathrm{nA}$ & 2 \\
\hline Pulse width, $\mathrm{ns}$ & 7 \\
\hline Bunching intervals, $\mathrm{ps}$ & 960 \\
\hline Pulse frequency, $\mathrm{kHz}$ & 11 \\
\hline The measured mass range, $\mathrm{m} / \mathrm{z}$ & $0.5-3000$ \\
\hline $\begin{array}{c}\text { Total ion doses in } \\
\text { measurements, ions } \cdot \mathrm{cm}{ }^{-2}\end{array}$ & $<1 \times 10^{12}$ \\
\hline $\begin{array}{c}\text { Detected secondary ions } \\
\text { Area of analysis for chemical } \\
\text { mapping, } \mu \mathrm{m}^{2}\end{array}$ & $\begin{array}{c}\text { positive and } \\
\text { negative }\end{array}$ \\
\hline
\end{tabular}




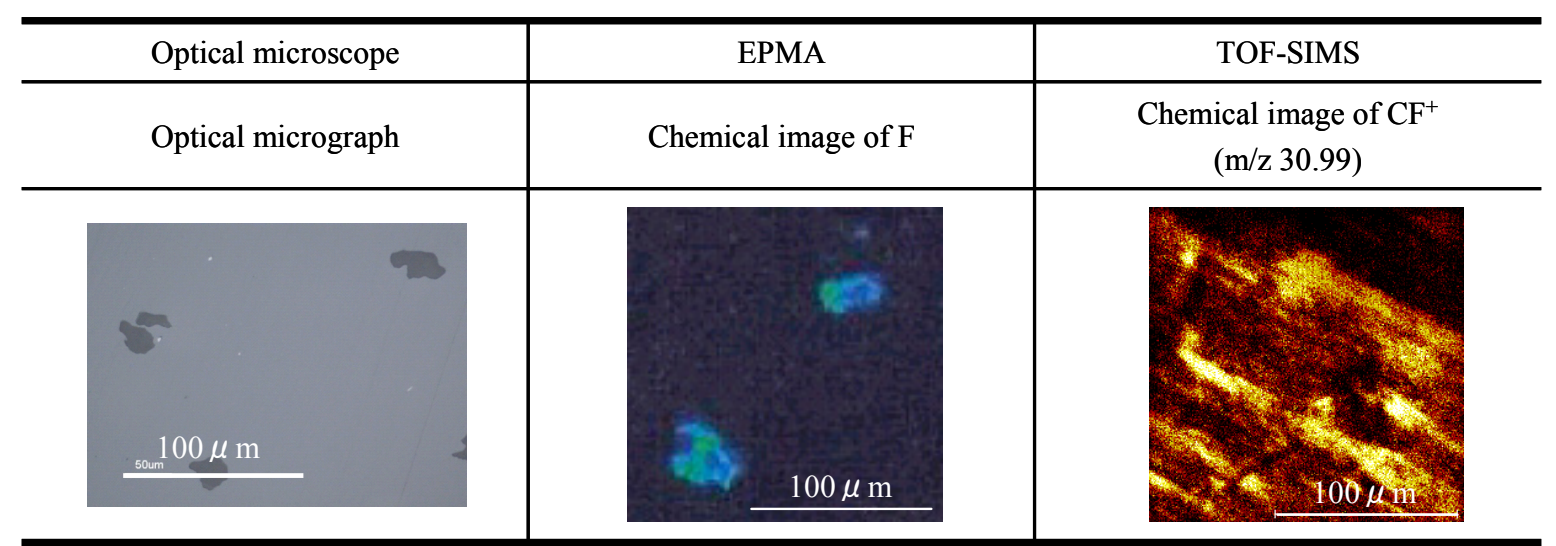

Figure 2 Morphology and chemical images of virgin PEEK-PTFE (6 mass\%) surface

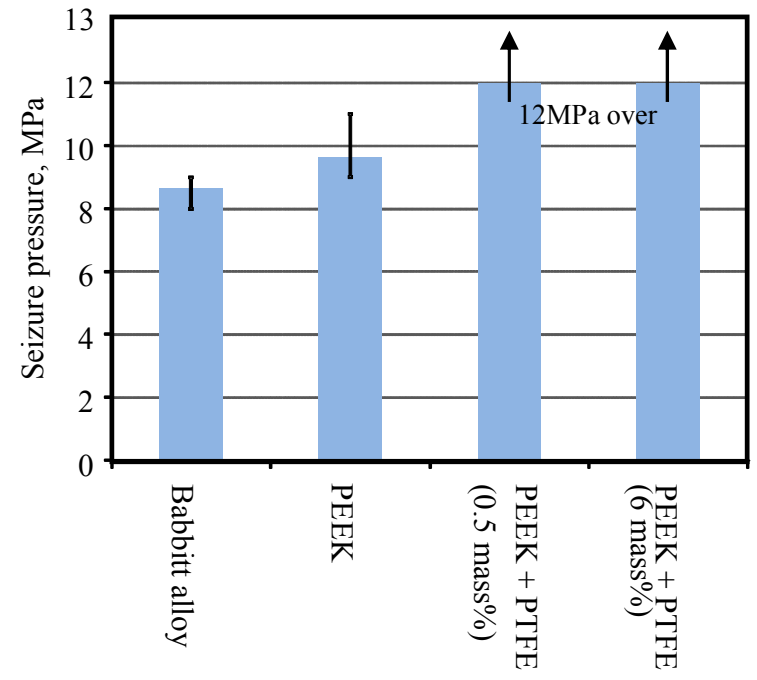

Figure 3 Load-carrying capacity of materials physically (as organic fluorides) and chemically (as iron fluorides).

Taking these results into account, the role of PTFE in improving the load-carrying capacity of PEEK can be summarized in Figure 7. PTFE exists as thin film on virgin PEEK surface. The transfer of PTFE onto the counter surfaces took place during rubbing. As the results, both of the rubbing surfaces are covered with PTFE. Since PTFE is well known as solid lubricants, formation of thin film composed of PTFE on the surface is being beneficial to reduce friction. Therefore, the tribological properties were improved.

It is empirically known that the blending of PTFE in PEEK improves the tribological properties ${ }^{3-8)}$. In the present work, we focused on the role of PTFE from viewpoint of surface chemistry. We wish to note that the present fundamental study has been applied to material design to meet practical applications ${ }^{10)}$.

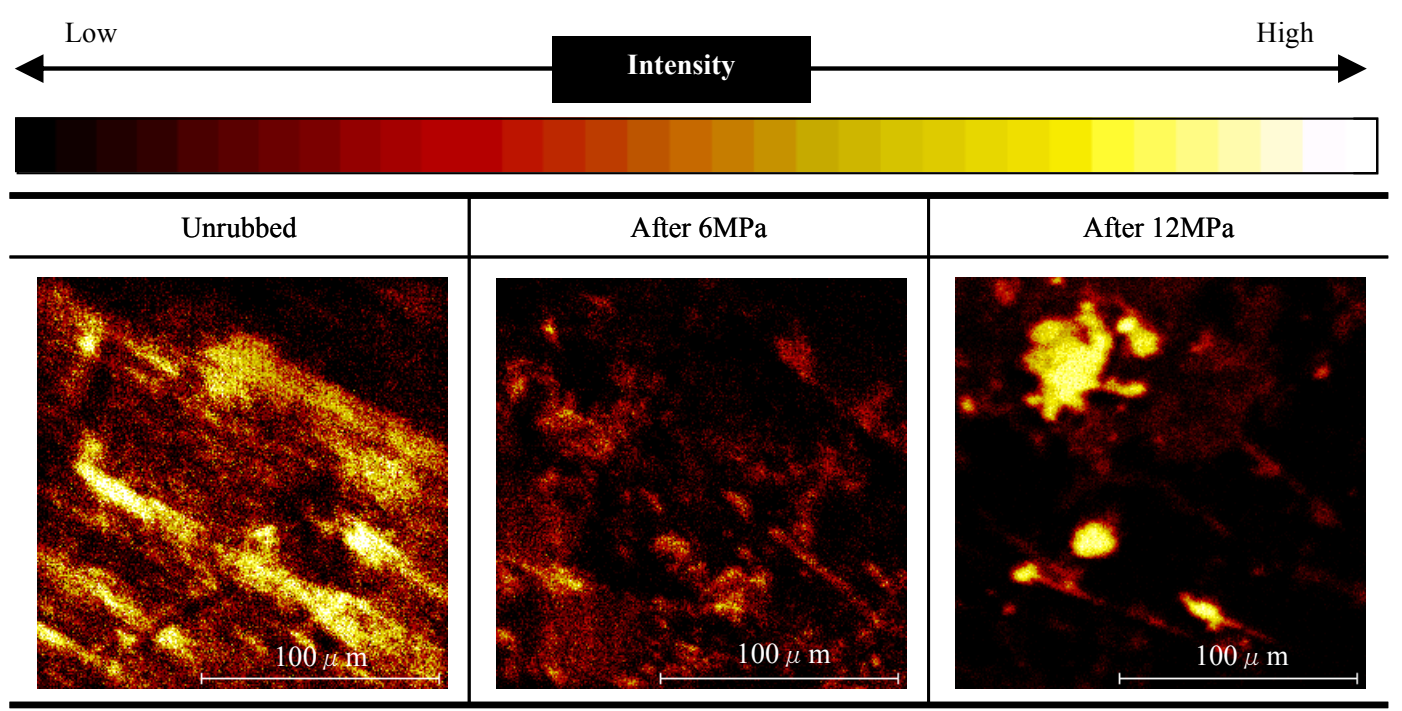

Figure 4 Chemical images of $\mathrm{m} / \mathrm{z} 31\left(\mathrm{CF}^{+}\right)$on rubbed PEEK-PTFE (6 mass\%) surface 

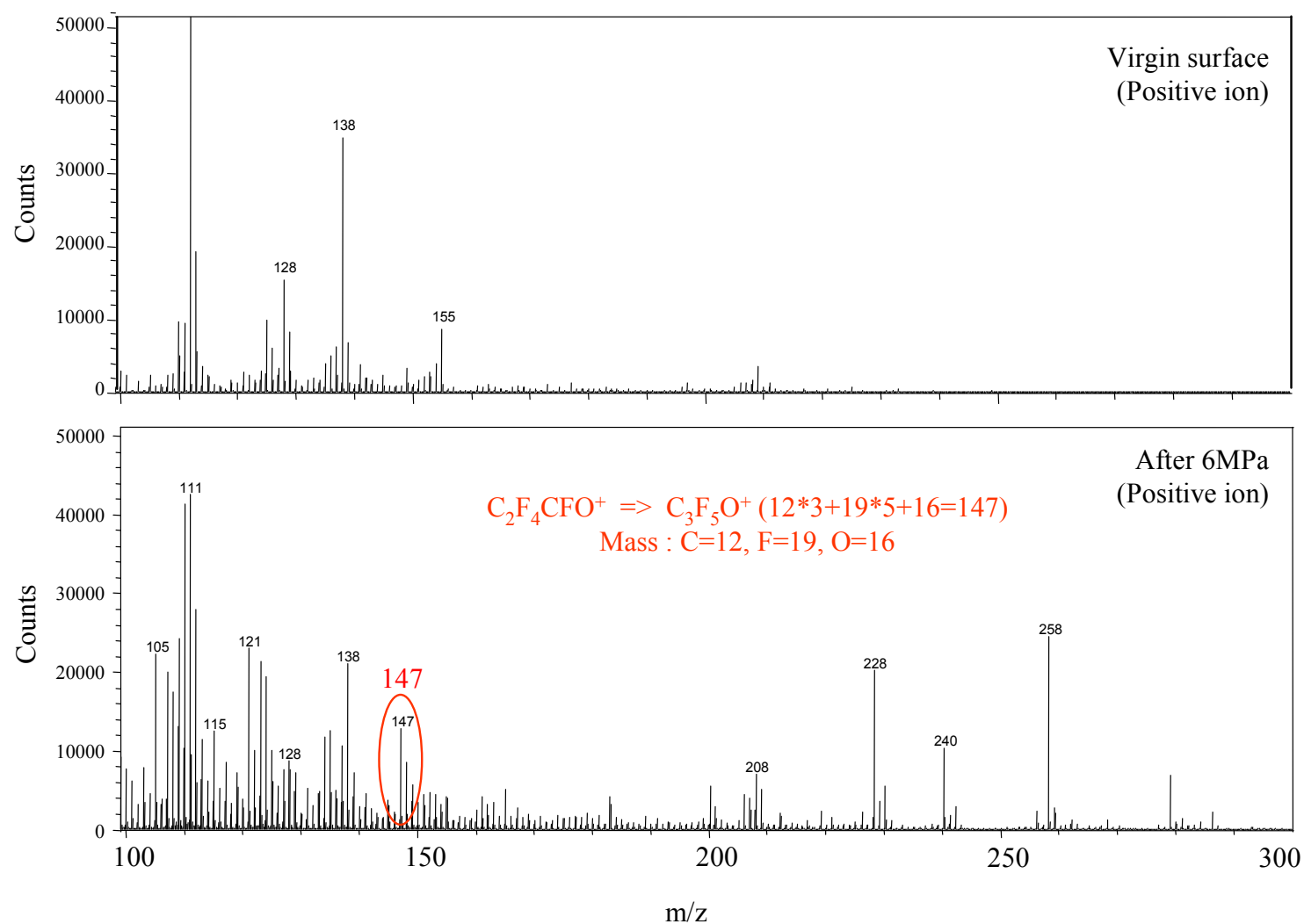

Figure 5 TOF-SIMS spectra of rotating ring surface (steel)

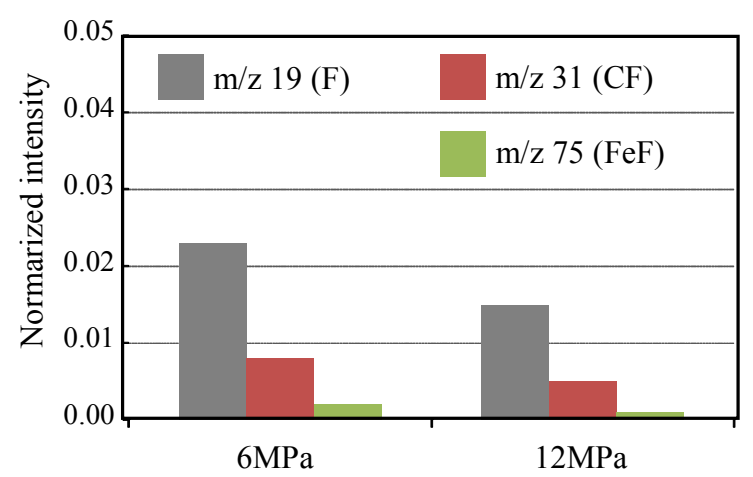

\section{Conclusions}

Addition of PTFE in PEEK remarkably improved the load-carrying capacity of PEEK-based composites. TOF-SIMS analysis of the rubbed surface afforded the chemical contents on uppermost surfaces of wear track. The results indicate that transfer of PTFE onto the counter surface takes place under the tribological conditions. The importance of surface chemistry in designing new tribo-materials was suggested.

Figure 6 Fluorine contents on rubbed steel surfaces
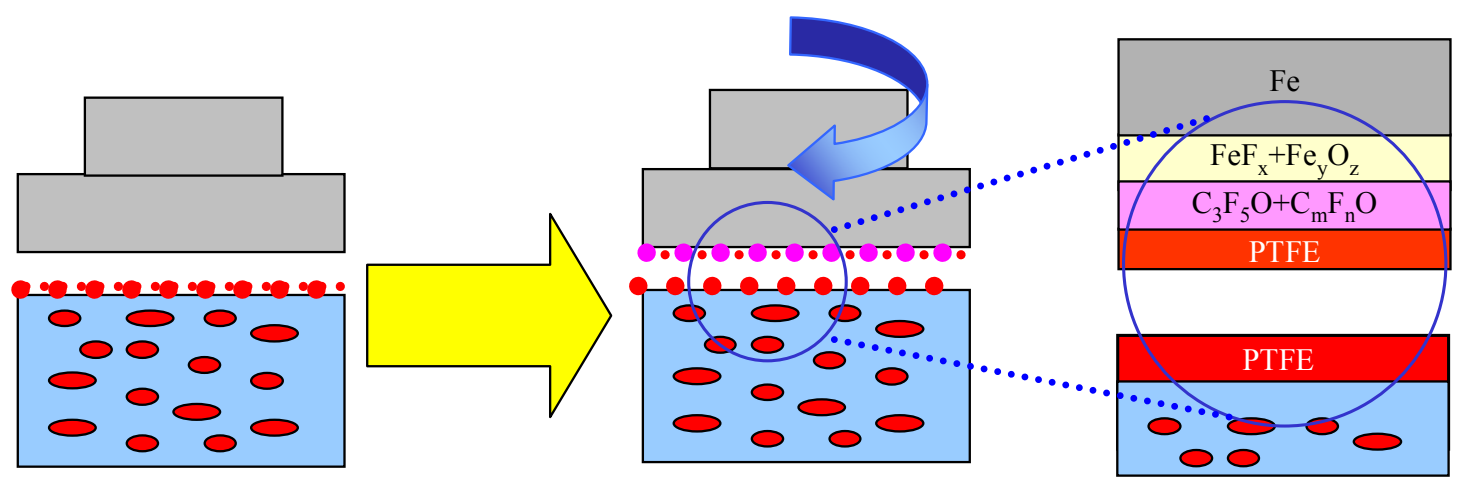

Figure 7 Proposed mechanism for the role of PTFE on load carrying capacity 


\section{Acknowledgement}

This work was carried out as a part of the program of METI (Ministry of Economy, Trade and Industry of Japan) and was financially supported by NEDO (New Energy and Industrial Technology Development Organization, Japan).

\section{References}

[1] Voss, H. and Friedrich, K., "On the Wear Behavior of Short-Fibre-Reinforced Peek Composites," Wear, 116, 1, 1987, 1-18.

[2] Lal, B. and Mathur, G. N., "Tribo-Investigation of PEEK-Short Carbon Fibre Composites in Severe Testing Conditions," J. Synth. Lubr., 24, 3-4, 2007, 149-166.

[3] Briscoe, B. J., Yao, L. H. and Stolarski, T. A., "The Friction and Wear of Poly(Tetrafluoroethylene)-Poly(Etheretherketone) Composites: An Initial Appraisal of the Optimum Composition," Wear, 108, 4, 1986, 357-374.

[4] Hufenbach, W., Kunze, K. and Bijwe, J., "Sliding Wear Behaviour of PEEK-PTFE Blends," J. Synth. Lubr., 20, 3, 2003, 227-240.

[5] Zhang, Z., Breidt, C., Chang, L. and Friedrich, K., "Wear of PEEK Composites Related to Their Mechanical Performances,” Tribol. Int., 37, 3, 2004, 271-277.
[6] Bijwe, J., Sen, S. and Ghosh, A., "Influence of PTFE Content in PEEK-PTFE Blends on Mechanical Properties and Tribo-Performance in Various Wear Modes," Wear, 258, 10, 2005, 1536-1542.

[7] Burris, D. L. and Sawyer, W. G., "A Low Friction and Ultra Low Wear Rate PEEK/PTFE Composite," Wear, 261, 3-4, 2006, 410-418.

[8] Lal, B., Alam, S. and Mathur, G. N., "Tribo-Investigation on PTFE Lubricated PEEK in Harsh Operating Conditions," Tribol. Lett., 25, 1, 2007, 71-77.

[9] Benninghoven, A., Hagenhoff, B. and Niehuis, E., "Surface MS: Probing Real-World Samples," Anal. Chem., 65, 14, 1993, 630-640.

[10] Inami, S., Takayanagi, S., Kubo, K., Nanao, H., Minami, I. and Mori, S., "Effects of Fine-Dispersed PTFE on Load Carrying Capacity of PEEK," Lubrication Science, in press.

\section{Nomenclature}

$\begin{array}{ll}\text { PEEK } & \text { poly(ether-ether-ketone) } \\ \text { PTFE } & \text { poly(tetrafluoroethylene) } \\ \text { time of flight secondary ion mass } & \text { spectroscopy } \\ \text { EPMA } & \text { electron probe micro analysis } \\ \mathrm{m} / \mathrm{z} & \text { mass to charge ratio }\end{array}$

